БОНДЫРЕВА Светлана Константиновна - доктор психологических наук, профессор, академик Российской академии образования; ректор Московского психолого-социального университета (115191, Россия, г. Москва, 4-й Рощинский пр-д, 9A; avtor@трsи.ru)

САВРУЦКАЯ Елизавета Петровна - доктор философских наук, профессор кафедры философии, социологии и теории социальной коммуникации Нижегородского государственного лингвистического университета им. Н.А. Добролюбова (603155, Россия, г. Нижний Новгород, ул. Минина, 31а; savrutsk@mail.ru)

УСТИНКИН Сергей Васильевич - доктор исторических наук, профессор, декан факультета международных отношений, экономики и управления, профессор кафедры международных отношений и политологии Нижегородского государственного лингвистического университета им. Н.А. Добролюбова (603155, Россия, г. Нижний Новгород, ул. Минина, 31а); директор Приволжкского филиала ФНИСЦ РАН (603000, Россия, г. Нижний Новгород, Холодный пер., 4; sv.ustinkin@gmail.com)

\title{
ЭКОЛОГИЯ ЯЗЫКА В ПРОБЛЕМНОМ ПОЛЕ СОВРЕМЕННЫХ ГЛОБАЛИЗАЦИОННЫХ ПРОЦЕССОВ
}

\begin{abstract}
Аннотация. Статья посвящена рассмотрению места и роли языка в системе культурных кодов на современном этапе развития глобализации. В рамках философско-лингвистического подхода авторы доказывают, что накопление и воспроизводство социокультурного опыта, осуществление духовно-нравственной преемственности и конструирование коммуникативной реальности в современных условиях цивилизационного развития общества связано с возрастающей ролью языка в реализации этих процессов. Приоритетную роль в сохранении чистоты национальных языков, обеспечении богатства речевой культуры играют семья и институты образования, благодаря чему закрепленные в языке факты и явления человеческой истории приобретают характер уникального механизма сохранения этнокультурной преемственности и определения оснований этнокультурной идентичности, остаются важнейшим элементом богатейшего комплекса культурных кодов этносов.
\end{abstract}

Ключевые слова: язык, культурные коды, образование, семья, коммуникация, образовательное пространство, языковая картина мира, коммуникативное действие, социальный опыт, этнокультурная идентичность

П одобно тому как природа требует бережного отношения к своему естественному состоянию и весьма избирательно относится к попыткам ее подчинения человеком в угоду все возрастающим потребностям своего развития, так и язык, выполняющий присущие ему функции сохранения национальных культур и обеспечения социальных связей между людьми, крайне болезненно относится к любым инородным вмешательствам в его структуру, лексику, нормы речевой культуры. Как уникальный механизм сохранения этнокультурной преемственности и определения оснований этнокультурной идентичности язык является важнейшим элементом богатейшего комплекса культурных кодов этносов.

В системах национально-культурных кодов язык, как и другие знаковые системы, наряду с традициями, обычаями и обрядами, архитектурными сооружениями, произведениями искусства сакрального характера, этикетами, играми, нормами и правилами поведения, играл и играет особую роль в упорядочении общественных процессов и сохранении целостности и этнокультурной уникальности социумов [Лотман 1996: 40, 98]. Виртуализация социального пространства современной цивилизации, вызванная процессами глобализации и бурного развития новых информационно-коммуникативных технологий, изме- 
няет содержание и конфигурацию систем этнокультурных кодов. В условиях нового цифрового мира многие виды культурных кодов, в частности традиции, обычаи, обряды, игры и ряд других, утратили прежние приоритеты в качестве важнейших механизмов сохранения и трансляции социального опыта в ряду поколений и оснований этнокультурной идентичности. Основная нагрузка по организации социальных практик людей и регулированию коммуникационных процессов в настоящее время падает на язык, обеспечивающий возможность понимания значений и смыслов используемых знаковых систем, норм поведения и механизмов социокультурной преемственности в современных условиях цивилизационного развития общества.

Вместе с тем язык как уникальный механизм обеспечения глубинных связей человека, этноса и биосферы может играть и разрушающую роль не только в межличностном общении, но и в этнокоммуникативных процессах социокультурного взаимодействия. Очевидно, что языковая реальность все более начинает занимать лидирующие позиции в формировании жизненного мира человека, порождая новый тип коммуникативного поведения, новую конфигурацию культурно-коммуникативного пространства современной цивилизации. Как одна из важнейших форм сохранения и трансляции интерсубъективного опыта современная языковая картина мира испытывает на себе большое влияние новых информационно-коммуникативных технологий, оказывающих многостороннее воздействие не только на возможность получения знаний, но и на процессы трансформации привычных методов обучения и воспитания, обеспечиваемых институтами образования и семьи [Шмидт, Коэн 2013: 30-32, 47-50].

Как один из определяющих культурных кодов современности язык выполняет роль адаптационного механизма вхождения человека в предметновещественный и духовный мир в условиях глобализации. В языке находит выражение и закрепляется этническая картина мира, формируется логика этноса, определяются основания и критерии этнокультурной идентичности. Коррективы в трансформацию кодовых систем, вносимые процессами глобализации, увеличивают роль языка в обеспечении целостности и устойчивости культурно-коммуникативного пространства этносов, в связи с чем проблемы языка все больше вписываются в политический контекст, обретая формат лингвистической безопасности в общей парадигме национальной безопасности страны.

Политическая и социокультурная значимость рассматриваемой проблемы очевидна в связи с тем, что характерные для глобализации процессы унификации втягивают «в свою орбиту “одинаковости” не только моду, средства связи, элементы предметно-вещественной среды, но и языковые модели, формы поведения, системы ценностей» [Савруцкая, Семенов 2017]. И в этой связи сохранение чистоты национальных языков является важнейшим условием сохранения национальных культур и национальных образов мира - определяющих признаков социокультурной преемственности и оснований этнокультурной идентичности. Эта проблема приобретает особую значимость в контексте современного этапа развития российской цивилизации, необходимости сохранения культурных оснований русского мира, грозящего раскола в православной ветви христианства. Как в теоретико-методологическом, так и в практическом планах эти проблемы замыкаются на необходимости сохранения норм речевой культуры на уровне делового и повседневного общения, чистоты и целостности русского языка как языка государственного и языка межнационального общения.

В условиях формирующегося нового мирового порядка и проявления еще до 
конца не обретшего определенные очертания наступающего периода постглобализационного развития мировой цивилизации возникает вопрос, какие факторы социальной среды оказывают наибольшее формирующее воздействие на ценностные ориентации, в частности, учащейся молодежи, что находит непосредственное отражение в языке, богатстве его словарного состава, нормах речевой культуры. Как показали результаты пролонгированного социологического исследования ценностных ориентаций обучающейся молодежи г. Нижнего Новгорода и Нижегородской обл., которое проводилось учеными НГЛУ при поддержке Министерства науки и образования Нижегородской области в 2006, 2011, 2014, 2015 и 2016 гг., факторами наибольшего влияния на формирование ценностного сознания молодежи являются Интернет и СМИ, семья, институты образования и среда межличностного общения, т.е. друзья, сверстники, одноклассники и др. [Савруцкая и др. 2017] (см. табл. 1).

Таблица 1

Факторы влияния на политические взгляды молодежи, в \% по гг.

\begin{tabular}{|c|c|c|c|c|}
\hline Годы & Интернет и СМИ & Родители & Школа (вузы, ссузы, школа) & Друзья \\
\hline 2006 & 72,3 & 33,0 & 20,4 & 13,0 \\
\hline 2011 & 63,3 & 34,5 & 16,9 & 23,2 \\
\hline 2014 & 70,2 & 33,2 & 21,6 & 18,4 \\
\hline 2015 & 70,8 & 45,3 & 35,0 & 26,4 \\
\hline 2016 & 76,0 & 40,4 & 35,1 & 26,8 \\
\hline
\end{tabular}

Естественно предположить, что эти же факторы играют приоритетную роль и в сохранении чистоты национальных языков, обеспечении богатства речевой культуры. В рамках данной статьи позволим себе остановиться только на одном из аспектов рассматриваемой проблемы - на роли институтов образования и семьи в духовно-нравственном воспитании молодежи и упорядочении коммуникационных процессов, прежде всего в сфере виртуальной коммуникации. Очевидно, что многообразие социальных практик, формируемых в современных условиях, невозможно без использования культурных кодов, в первую очередь - языковых моделей. Возникающие в процессе обучения и семейного воспитания системы знаний и социальных практик закрепляются и устойчиво сохраняются в языковой картине мира, вбирающей в себя все разновидности социального опыта, формирующегося под влиянием изменяющихся обстоятельств повседневности и цивилизационного развития общества.

Важнейшим моментом в понимании особенностей исторически сложившихся связей между языком, культурой и нормами поведения является разработанная известными американскими лингвистами Э. Сепиром и Б. Уорфом концепция, согласно которой в языке заложены нормы мышления, оказывающие влияние на нормы и направленность (вектор) поведения. В этой связи Б. Уорф пишет: «Мы должны признать влияние языка на различные виды деятельности людей не столько в особых случаях употребления языка, сколько в его постоянно действующих законах и в повседневной оценке им тех или иных явлений» [Уорф 2003: 158].

Прослеживая исторические пути этнокультурного и нормативно-поведенческого развития, Б. Уорф отмечал, что в принципе поведенческие нормы и языко- 
вые модели сосуществовали синхронно, оказывая взаимное влияние. Однако в языке всегда происходило жесткое ограничение свободы выбора. Иначе говоря, в языке соблюдается строгое следование сложившейся языковой традиции, в то время как в поведенческих нормах всегда ярче выражены элементы ситуативности и релятивизма. В силу своей консервативности язык как этнокультурная кодовая система надолго сохраняет отраженные в ней социальные смыслы, речевые стандарты и нормы речевой культуры и поведения. Очевидным положительным моментом консерватизма языка является возможность сохранения благодаря этой особенности тех ценностей, которые в первую очередь регламентируют нормы поведения человека и отношения между людьми, обеспечивая тем самым преемственность в историко-культурном процессе.

Положительная роль лингвистической устойчивости проявляется и в том, что она способствует сохранению стандартов культуры речи и особенностей национальных культур, несмотря на разноплановое влияние Интернета и СМИ на лингвокоммуникативную и поведенческую сферы современного социума. В силу этой особенности взаимозависимости и связи поведенческих норм и языковых моделей становится очевидной необходимость сохранения чистоты и культуры как родного языка, так и языка межнационального общения в странах, отличающихся многонациональным составом населения.

Не менее важным для понимания приоритетной роли семьи и институтов образования в сохранении чистоты языка является и тот факт, что изменения в предметно-вещественной среде, духовно-ценностных ориентациях и формах коммуникативного действия (Ю. Хабермас) осуществляются быстрее, чем в языке. Закрепившись в речевых единицах этнических общностей и социальных групп, языковые обозначения способны надолго удерживать сложившиеся образы мира, упорядочивая или разрушая системы существующих культурных стереотипов. В значительной мере «реальный мир», как утверждает Э. Сепир, «неосознанно строится на основе языковых привычек той или иной социальной группы» [Сепир 2003: 131]. К примеру, в современных условиях под влиянием новых информационно-коммуникативных технологий разрушающая сила трансформации русского языка все еще скрыта за многообразием ранее устоявшихся моделей речевого взаимодействия, все еще сохраняющихся в языке историко-культурных традиций и этикетных поведенческих стереотипов. Но по мере вхождения в процессы общественного развития новых поколений, вобравших в себя реалии вновь формирующихся общественных процессов и стандартов языка, будут меняться и картина мира, и социокультурные смыслы, теряющие связь с историко-культурными традициями своей страны. Уже сейчас становится заметным, зачастую на неосознаваемом уровне, влияние передаваемой языковыми средствами информации на массовое поведение и ценностное сознание тех или иных групп населения. Особенно заметно эта тенденция проявляется в сфере политических установок и повседневных оценочных взглядов относительно социально значимых событий и явлений действительности. Наглядным примером использования языка как средства политического воздействия является запрещение на Украине русского языка на всех уровнях социальной коммуникации. В выборе же средств осуществления националистической доктрины неофашистской направленности в борьбе против России и российской цивилизации режимом Порошенко утверждается триада «Армия. Религия. Язык», в которой язык по силе воздействия на национальное самосознание и формы поведения находится в одном ряду с духовно-нравственным и физическим способами убеждения и принуждения. Примечательно в этом же контексте мнение госсекретаря США Аллена Даллеса, который в 1948 г. писал: «Чтобы развалить СССР, не надо атомной бомбы, нужно только внушить его народам, что они могут обойтись без 
знания русского языка. Нарушатся экономические, культурные, другие связи. Государство перестанет существовать» [Бартош 2014].

В современных условиях глубинных цивилизационных изменений, когда происходит разрушение культурных кодов, обеспечивающих сохранение и воспроизводство определяющих признаков национальных культур, а контуры новых отношений наступающего постглобализационного периода общественного развития еще не определились, семья и институты образования являются одними из самых устойчивых носителей национальных культур, духовнонравственных традиций и религиозных ценностей, надежно сохраняющихся и транслирующихся на новые поколения благодаря языковой картине мира.

Однако в исследованиях отечественных и зарубежных ученых отмечается, что в современных условиях обозначилась весьма ощутимая тенденция ослабления родительской мотивации к общению с детьми (Д. Фельдштейн, Д. Коэн). В отношении современных родителей к детям можно обнаружить забвение «ответственности взрослого общества за детей» и утрату «причастности Взрослого Мира к Детству». В «целом ...нет устойчивой иерархии разнообразных связей, системного взаимодействия», что существенно усложняет действие механизмов социальной преемственности [Фельдштейн 2013]. В исследованиях по проблемам современной семьи отмечается также, что «семья превращается из терминальной ценности в инструментальную» [Готово ли российское... 2010: 226, 338]. В этой связи отмечается, что в настоящее время происходит «не столько модернизация семейной сферы, связанная с плюрализацией форм семейной жизни, сколько прагматизация партнерских отношений», когда не индивид «служит интересам семьи, а семья все чаще становится лишь элементом в системе обеспечения интересов человека» [Готово ли российское...2010: 328]. По этой причине, на наш взгляд, в условиях становления нового мирового порядка, развития новых цивилизационных отношений и информационно-коммуникативных технологий, а также разрушения системы традиционных национально-культурных кодов, обеспечивающих процессы этнокультурной преемственности, молодежь оказалась поставленной лицом к лицу с проблемой собственного выбора ценностных ориентаций и жизненных установок, зачастую не имея возможности опереться на социокультурный опыт старших поколений.

В контексте российского варианта рассматриваемой проблемы нельзя не учитывать и тот факт, что семейные ценностные ориентации той части молодежи, которая формировались в бурные 1990-е гг., отличались резкой поляризацией ценностных установок массового сознания «отцов» и «детей». Крайний негативизм в оценке всего, связанного с историческим прошлым России, слепое поклонение западным идеалам и ценностям, попытка трансформировать все сферы российской реальности в соответствии с западными либеральными ценностями и стандартами образа жизни без учета историко-культурных традиций своей страны сильно повлияли на ослабление престижа семьи как фактора формирования ценностных установок подрастающего поколения.

Есть еще одна проблема, ощутимо дающая о себе знать, создающая естественный информационно-коммуникативный барьер между преобладающей частью «отцов» и «детей». Дело в том, что интернет-технологии подняли престиж виртуальной коммуникации на столь высокий уровень, что «простота человеческого общения», которая была возможна прежде всего в семье и которая представляет ничем не заменимую социальную среду для формирования духовно-нравственного мира человека, оказалась бессильной перед натиском образов виртуальной реальности, создаваемых симуляционными технологиями, социальными сетями, яркими образами шоу-бизнеса. Эти особенности современного состояния рассматриваемой проблемы роли семьи как одного 
из важнейших факторов социокультурной преемственности выдвигают перед обществом ряд задач, способствующих минимизации негативных последствий возможных информационно-коммуникативных барьеров между поколениями. С этой целью, на наш взгляд, необходимо, во-первых, разработать новую, соответствующую особенностям новых цивилизационных условий парадигму образования и воспитания современных «растущих людей», но для этого необходимо время, т.к. их «новизна» только разворачивается в пространстве так называемых постглобализационных процессов. А во-вторых, следует признать, что в коммуникативных пространствах старших и младших поколений возможно достаточно длительное сохранение разных измерений ценностных ориентаций, которые сосуществуют по многим жизненно важным параметрам не только в параллельных, но и в противоположных плоскостях. По этим причинам основная нагрузка в адаптации молодых поколений к быстро меняющимся условиям «расширенной объективно-виртуальной реальности» [Макеев 2017: 122] ложится на институты образования, становящиеся в современных условиях важнейшим каналом связи между структурами общества как системы. При этом институты образовании используются государством и для унификации сферы культуры, являющейся, по справедливому замечанию П. Бурдье, «основополагающим элементом строительства национального государства» [Бурдье 2007: 234].

Важнейшим моментом, раскрывающим многоаспектность связи языка и многогранной деятельности институтов образования, является проблема обеспечения экономической и военной безопасности нашей страны, а также ее культурного выживания, условием решения которой является подготовка квалифицированных кадров, осуществляемая системами образования и науки. В проблемном пространстве институтов образования язык как этнокультурный код занимает особое место и играет особую роль, определяемую следующими особенностями.

Во-первых, языковая реальность в контексте учебно-образовательной деятельности характеризуется как канал двунаправленной связи, что приобретает особую социокультурную значимость в условиях многонациональных государств и особенностей переходного периода к новым цивилизационным процессам общественного развития. Образование как вид деятельности осуществляется в форме речевого взаимодействия учитель - ученик, что предполагает: 1) активную обратную связь и достаточную растянутость по временному показателю; 2) многообразие предметно-образовательной деятельности, что постоянно увеличивает богатство лексики, единицы которой находятся в более или менее активном состоянии в связи с необходимостью их использования в образовательном процессе с целью его систематизации; 3) что образы виртуального мира, закрепленные в языковых формах, носят некодированный характер, т.е. непосредственной привязки образа и слова (символа, знака) к реальному событию или предмету в большинстве случаев нет. И с этим символическим миром для институтов образования возникает масса проблем, связанных с тем, что в современном коммуникативном пространстве благодаря высокотехнологичным средствам связи умножаются и ускоряются коммуникативные процессы, на содержание и наполняемость которых все большее влияние оказывают не реальные, рациональные денотации объектов, а их целенаправленно конструируемые образы. По мнению Э. Тоффлера, большая часть этих образов строится на основе информационных сообщений, созданных человеком, «а не на основе личных наблюдений “некодированных” явлений» [Тоффлер 2004: 187]. При этом он отмечает, что в коммуникативном пространстве новые образы - волна за волной - разрушают «оборону» и «мысленную модель реальности», приводя 
к ускоренному вытеснению старых образов, увеличению умственной «пропускной способности» и глубокому ощущению непостоянства, недолговечности, неустойчивости самого знания [Тоффлер 2004: 184].

Трудности, стоящие перед институтами образования, усугубляются и тем, что образовательные системы достаточно консервативны по своей природе. По этой причине они не успевают за скоростью изменений социальных процессов, в силу чего образование не имеет подтвержденных на практике теоретически обобщенных выводов о том, какое влияние социальные трансформации оказывают на духовный мир человека, какие модели обучения и воспитания должны прийти на смену ныне существующим. Однако современные условия цивилизационного развития общества требуют от институтов образования большей мобильности, прежде всего в сфере своей организации и функционирования при переходе к новым инновационным доминантам своего развития при сохранении традиционности и устойчивости определяющих признаков национальных культур. Институты образования как центры обучения и воспитания молодых поколений в своей деятельности способствуют сохранению устойчивости традиционных историко-культурных и культурно-коммуникативных элементов общества как системы преимущественно благодаря консервативности языка. Как генетический и культурный код народа язык, прежде всего благодаря семье и институтам образования, обеспечивает самовоспроизводство социума на традиционных духовнонравственных основаниях, благодаря чему также осуществляется воспроизводство целостности и культуры языкового поля современного коммуникативного пространства.

В настоящее время складывается особая коммуникативная ситуация, при которой функционирование определяющих факторов коммуникативного пространства обеспечивается большим числом новых медиа, заменяющих традиционные каналы трансляции системы ценностей и создающих качественно иную информационную среду [Zhigalev et al. 2017]. Новый мир цифровых технологий несет в себе огромные пласты новых возможностей для развития научных знаний и их практического применения в области «инструментального действия». Однако развитие сетевого сообщества и цифровых технологий происходит в ущерб сфере «коммуникативного действия» [Хабермас 2000: 199]. Объясняется это прежде всего тем, что по мере увеличения доли виртуальной коммуникации в «расширенной реальности» возрастает угроза катастрофического сужения возможностей влияния нравственных норм и духовной преемственности в регламентации коммуникационных процессов и реализации гуманистических принципов отношений между людьми.

\section{Список литературы}

Бартош А. 2014. Лингвистическая безопасность страны. - Независимое военное обозрение. Доступ: http://nvo.ng.ru/concepts/2014-02-14/1_model.html (проверено 01.03.2019).

Бурдье П. 2007. Дух государства: генезис и структура бюрократического поля. - Социология социального пространства. М.: Институт экспериментальной социологии; СПб: Алетейя. 288 с.

Готово ли российское общество к модернизации? (под ред. М.К. Горшкова, Р. Крумма, Н.Е. Тихоновой). 2010. М.: Весь Мир. 344 с.

Лотман Ю.М. 1996. Внутри мыслящих миров. Человек- текст -семиосфера история. М.: Языки русской культуры. 464 с.

Макеев С.Н. 2017. Феномен социального общения в пространстве расширенной объективно-виртуальной реальности: дис. ... к.филос.н. Саранск. 148 с. 
Савруцкая Е.П., Жигалев Б.А., Викулина М.А., Макшанцева Н.В. 2017. Институты образования и молодежь: на пути устойчивого развития общества. Н. Новгород: Изд-во НГЛУ. 184 с.

Савруцкая Е.П., Семенов Д.В. 2017. Культурные коды конструирования новой культурно-коммуникативной реальности. - Единая российская нация: проблемы формирования ее идентичности: сборник статей участников всероссийской научно-практической конференции. Арзамасский филиал ННГУ; Фонд «Русский мир». Саров: Интерконтакт. С. 38-42.

Сепир Э. 2003. Статус лингвистики как науки. - Языки как образ мира: антология. М.: АСТ; СПб: Terra Fantastica.

Тоффлер Э. 2004. Шок будущего (пер. с англ.). М.: АСТ. 557 с.

Уорф Б.Л. 2003. Отношение норм поведения и мышления к языку. - Языки как образ мира: антология. М.: АСТ; СПб: Terra Fantastica.

Фельдштейн Д.И. 2013. Функциональная нагрузка Академии образования в определении принципов и условий развития растущего человека на исторически новом уровне движения общества: доклад на общем собрании РАО. 29 октября 2013 г. - Проблемы современного образования. № 5. Доступ: http://pmedu.ru/ res/2013_5_2(проверено 01.03.2019).

Хабермас Ю. 2000. Моральное сознание и коммуникативное действие. СПб: Наука. 377 с.

Шмидт Э., Коэн Д. 2013. Новый цифровой мир. Как технологии меняют жизнь людей, модели бизнеса и понятие государства. М.: Манн, Иванов и Фербер. 368 с.

Zhigalev B., Savrutskaya E., Sdobnikov V., Ustinkin S. 2017. Influence of Migration Processes on Modern Communicative Space and Ethnicities' Cultural Patterns. - 4th International Multidisciplinary Scientific Conference on Social Sciences and Arts SGEM 2017. P. 337-350.

BONDYREVA Svetlana Konstantinovna, Dr.Sci. (Psych.), Professor, Academician of the Russian Academy of Education; Rector of Moscow Psychological and Social University (9a $4^{\text {th }}$ Roshinsky Pass, Moscow, Russia, 115191; avtor@mpsu.ru) SAVRUTSKAYA Elizaveta Petrovna, Dr.Sci. (Philos.), Professor; Professor of the Chair of Philosophy, Sociology and Theory of Social Communication, Dobroljubov State Linguistics University of Nizhny Novgorod (31a Minina St, Nizhny Novgorod, Russia, 603155; savrutsk@mail.ru)

USTINKIN Sergei Vasil'evich, Dr.Sci. (Hist.), Professor, Dean of the Faculty of International Relations, Economy and Management, Professor of the Chair of International Relations and Political Science, Dobroljubov State Linguistics University of Nizhny Novgorod (31a Minina St, Nizhny Novgorod, Russia, 603155); Director of Volga branch of the Federal Center of Theoretical and Applied Sociology, Russian Academy of Sciences (4 Holodnyi Lane, Nizhny Novgorod, Russia, 603000; sv.ustinkin@gmail.com)

\section{THE ECOLOGY OF LANGUAGE IN THE CONTEXT OF MODERN GLOBALIZATION PROCESSES}

Abstract. The article is devoted to the analysis of the place and role of language in the system of cultural codes at the present stage of globalization development. Within the philosophical and linguistic approach, the authors prove that the accumulation and reproduction of sociocultural experience, the implementation of spiritual and ethical continuity and the construction of communicative reality in the modern conditions of civilizational development of society is connected with the increasing role of language in the realization of these processes. Family and educational institutions play a priority role in the preservation of national languages' purity, the creation of speech culture wealth. Thanks to this, phenomena of human history fixed in language acquire the character of a unique mechanism of preserving ethnocultural continuity and the identification of ethnocultural identity base, and remain the most important element of the richest complex of ethnic groups' cultural codes.

Keywords: language, cultural codes, education, family, educational space, language world picture, communicative act, social experience, ethnocultural identity 